\title{
Bicycing-related accidents and factors contributing to injury
}

\author{
Luis Miguel GONZALEZ-PEREZ \\ Virgen del Rocio University Hospital. Seville, Spain. \\ Johan WIDEBERG, Professor Transportation Engineering \\ Borja GONZALEZ-PEREZ-SOMARRIBA, MSc students \\ ETSI, University of Seville.
}

\begin{abstract}
:
Objective: This study was conducted to find the epidemiological characteristics of bicycling-related maxillofacial fractures in a defined population, and identify factors contributing to injury.

Methodology: A prospective study was carried out involving patients presenting with maxillofacial fractures sustained in bicycling-related accidents.

Results: Between 908 of all cycling accidents attending for medical treatment, 122 patients (13\% of all cycling accidents) were admitted with facial fractures between 2007 and 2014. Male and female ratio was 2.6:1, and the mean age was 29.4 years (standard deviation: 12.8, range: 12-79 years). Causes of injury included collisions (63\%) and accidental falls (37\%). The fracture patterns seen were mandibular (49\%), zygomatic (32\%), orbital (13\%), nasal $(7 \%)$, maxillary (2\%), and frontal (2\%). Condylar fractures were the most common of the mandibular fractures (63\%). The most frequently observed concomitant lesions were orthopedic injuries.

Conclusions: Bicycling-related maxillofacial injuries are common and therefore important to identify in order to design a sustainable transport system and for units that provide assistance to traffic accident victims. Missed diagnosis or delayed treatment can lead to facial deformities and functional problems. Wearing protective helmets and the improvement of the helmets design is one aspect that would be of interest for the prevention of injuries.
\end{abstract}

Keywords: Cycling; bicycle-related trauma; maxillofacial fractures; risk factors; helmets.

\section{Introduction:}

Maxillofacial trauma is a common injury requiring multidisciplinary care which can occur as a result of various causes, such as traffic accidents, falls, assaults, and sports, in isolation or combination with other injuries. The epidemiology of these fractures depends on the geographic area, and the period of investigation. Different causes of maxillofacial fractures may be associated with different types and distributions of injuries (age, gender, site, severity of injuries); therefore, understanding these fractures may inform clinical research in the development of more effective prevention and treatment of these injuries ${ }^{1,2}$.

Bicycling is a fantastic form of transport and exercise among persons of all ages, but carries a risk of injury. Traffic accidents, including those involving bicycles, are among the most common causes of maxillofacial fracture, with bicycle accidents reportedly causing 2-18\% of facial fractures in published series ${ }^{3,4,5}$. Seville is a city that has experienced an almost 
unprecedented expansion of dedicated bicycle lanes and use of the bicycle. Before 2005 virtually no one used the bicycles for transportation, and it was used mainly for recreation and exercise. In 2006, an ambitious plan was set in motion and over $80 \mathrm{~km}$ of bicycle infrastructure was created the first year ${ }^{6}$. The city also put in place an ambitious bike hire scheme where the inhabitants can use bikes that they withdraw from docking stations. Bicycle modal share went from $0.5 \%$ in 2006 to $7 \%$ in 2013. The Copenhagenize index ${ }^{7}$ puts Seville in the $10^{\text {th }}$ place of bicycle friendly city in the world. With the increase of bicycle mobility, there has also been an increase in bicycle accidents ${ }^{8,9,10}$. The objective of this study was to find the epidemiological characteristics of bicycling-related maxillofacial fractures from year the 2007 in a defined population in the city of Seville, identify factors contributing to injury, and to present an analysis of the key risk factors that contributed to the accidents and identifies a set of countermeasures to improve bicyclist safety.

\section{Methodology:}

The present study was a prospective analysis of acute maxillofacial fractures sustained in bicycling-related trauma at the Department of Oral and Maxillofacial Surgery, and treated from January 2007 through October 2014.

Injuries sustained in cycling accidents were defined as while the patient was riding the bicycle. Hospital Episode Statistics data and injury and illness information was recorded using their clinical records and imaging studies and were analyzed for age, gender, date and cause of injury (including type and location of the crash), risk factors, type of facial fractures, injuries to other sites of the body, mean hospitalization and patterns of bicycle helmet use in our patients. Incomplete patient charts and only superficial trauma such as abrasions and contusions were excluded from this study. Data were analyzed with statistical software (IBM SPSS Statistics 19.0). The Research and Clinical Ethics Committee approved the study. Declaration of Helsinki guidelines was followed.

\section{Results:}

During the 8-year period considered in this study, between 908 of all cycling accidents attending for medical treatment, bicycle-related facial fractures occurred in 122 patients (13\%), 88 men (72\%) and 34 women (28\%), with a percentage of $6 \%$ among all facial fractures. Total numbers of fracture were 135, as some of the patients had multiple fractures. In total, $56 \%$ of them were single bicycle crashes. A mean age of 29.4 years (standard deviation: 12.8 , range: $12-79$ years) with a male: female ratio of 2.6:1 was observed. The number and gender of admitted patients per year with bicycling-related maxillofacial fractures is resumed in Table 1. According to decades of ages, most frequently involved patients were between 20 and 29 (43 patients, 35\%) as listed in Table 2. The incidence of bicycle-related maxillofacial injuries, according to months, is presented in Figure 1. The monthly distribution showed that months between April and September presented the highest incidence of facial fractures. There was a not significant variation in the incidence on different days of the week. 


\begin{tabular}{|l|l|l|l|}
\hline Year & Males & Females & Total Patients \\
\hline 2007 & 9 & 4 & 13 \\
\hline 2008 & 13 & 4 & 17 \\
\hline 2009 & 13 & 6 & 19 \\
\hline 2010 & 11 & 4 & 15 \\
\hline 2011 & 12 & 4 & 16 \\
\hline 2012 & 10 & 4 & 14 \\
\hline 2013 & 13 & 5 & 18 \\
\hline 2014 & 7 & 3 & 10 \\
\hline
\end{tabular}

Table 1: Admitted patients with bicycle-related maxillofacial fractures per year.

\begin{tabular}{|l|l|l|l|}
\hline Decades (years) & Males & Females & Total Patients \\
\hline $10-19$ & 23 & 8 & 31 \\
\hline $20-29$ & 30 & 13 & 43 \\
\hline $30-39$ & 15 & 6 & 21 \\
\hline $40-49$ & 13 & 4 & 17 \\
\hline $50-59$ & 4 & 1 & 5 \\
\hline $60-69$ & 3 & 1 & 4 \\
\hline $70-79$ & 0 & 1 & 1 \\
\hline
\end{tabular}

Table 2: Gender and age distribution of patients studied.

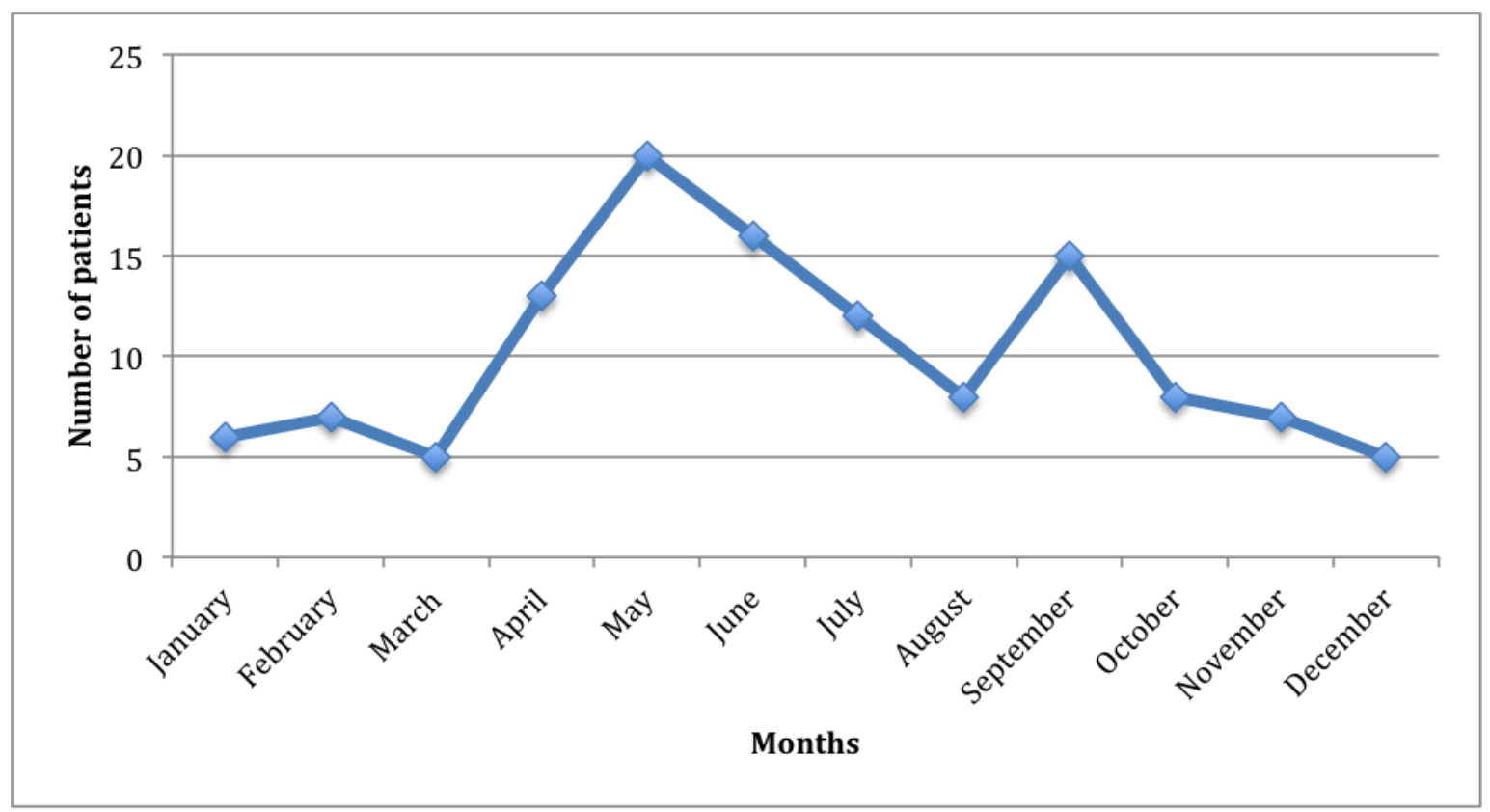

Figure 1: Admitted patients with bicycle-related maxillofacial fractures according to months during the considered time frame. 
Most common etiology of injury was collision (63\%), followed by accidental falls (37\%), many as a result of collision avoidance manoeuvres. Collisions included those with motor vehicles (20\%), infrastructure and other surface features (posts, curbs, and street furniture) $(33 \%)$, and pedestrians $(5 \%)$ or other cyclists $(5 \%)$. In this study, risk factors were found in 83 cases ( $68 \%$ of the patients) and some of the patients had multiple risk factors: cyclist did not wear helmet (33 patients, 27\%), motor vehicle involved (25 patients, 20\%), driving with headphones (23 patients, 19\%), cycling in early evening (21 patients, 17\%), unsafe cycling environment (rain, road works) (15 patients, 12\%), mechanical failures of bicycles (14 patients, $11 \%$ ), alcohol abuse (11 patients, $9 \%$ ), and competitive bicycle racing (10 patients, $8 \%)$.

The distribution of facial fractures showed that $93 \%$ of the patients had a single facial fracture. Cycling related injuries caused multiple facial fractures in $7 \%$ of patients. The fracture patterns seen were mandibular (60 patients, 49\%), zygomatic (39 patients, 32\%), orbital (16 patients, $13 \%$ ), nasal ( 9 patients, $7 \%$ ), maxillary (2 patients, $2 \%$ ), and frontal (2 patients, $2 \%$ ). Condylar fractures were by far the most common of the mandibular fractures (63\%). When no other concomitant lesions were present, mean hospitalization of the inpatients was 4 days (SD, 1.2 days). For all the patients in this study, $43 \%$ reported never wearing and $32 \%$ inconsistently wearing a helmet. Only $26 \%$ of students reported always wearing a bicycle helmet.

Concomitant lesions were found in 24 cases (20\% of patients) and, among all these, orthopedic injuries to the upper and lower extremities were the most frequently observed (42\%). Associated dental injuries were found in 33 cases (27\% of the patients), and the most frequently observed were dental fractures $(43 \%)$, followed by luxations $(32 \%)$ and avulsions (25\%). The most frequent injured site was the upper anterior tooth (80\% of the cases). Cranioencephalic injuries were observed in 7 patients (6\% of patients in the study period), and their existence was associated with a prolonged stay in hospital (30 \pm 7 days). None of the patients with associated cranial trauma were wearing a helmet at the time of the injury.

\section{Discussion:}

Traffic-related trauma continues to decrease with the advent of better safety devices in automobiles such as seatbelts and airbags, but the incidence of other etiologies has increased with the growth in popularity of activities like bicycling, as happens in the city of Seville with the creation of cycling lanes in 2006. Seville is located in the very south of Spain and also the south of Europe. It has approximately one million inhabitants and the city is very dense near the centre but also has a large extension when including suburbs and nearby villages. The city is very hot in the summer but the rest of the year is mild with a lot of sun and little wind. That and due to fact that it is a very flat city, without hills, makes it almost perfect for bicycles. Therefore it is strange that virtually no one used the bike for transportation before the beginning of this decade, bikes where mainly used for recreation and exercise. However, Seville is a city that has experienced an almost unprecedented expansion of dedicated bicycle 
lanes and use of the bicycle, and with this increase there has also been an increase in bicycle accidents. There are several reasons for this increase, the two most important once are the layout of the lanes and the lack of education how to use the bike safely. The bicycle lanes, due to the layout, enters into conflict with cars and also with pedestrians. In several places where the bike lane crosses and the vehicle lane there is bad visibility for the car drivers. This results in accidents where a car hits a bicyclist. The other main issue has been that there was virtually no information campaign on how to use the bicycle lanes i.e. the users didn't know how to behave, neither between bicyclists nor between vehicles and bikes.

Bicycling-related injuries constitute an important etiological mechanism of maxillofacial fractures, according to the various epidemiological studies 5,10-13, and differences in maxillofacial injury rates by geographic area may be explained by differences in exposure to bicycling, habits, and demographic characteristics of bicycle users. Injuries to cyclists are even more under-reported than other road users since single bicycle crashes are dominating and often unknown to the police. Therefore, hospital data are more relevant to use to analyze bicycle crashes 5,8 .

Boffano et al. ${ }^{14}$ have done an ambitious study on maxillofacial injuries related to bicycles comparing epidemiological data in two European centers from 2001 to 2010. Their findings have similar percentages of accidents and on the damage level as in our series. In our study, the incidence of bicycle-related fractures among all maxillofacial fractures has remained relatively constant between 2007 and 2014, although the number of bicycling-related injuries may have been underestimated in this study due to attribution of injuries to accidental falls or to unreported fractures. Undisplaced fractures with no physical complaints may have not involved medical intervention, and this may also have occurred in our report. Patients in this study were predominantly young males between their second to fourth decade of life, possibly due to higher risk-taking behaviours as well as cycling being a more common form of transportation in this age group in our city. Most serious fractures result from collisions with motor vehicles. Maxillofacial injuries are three times more likely in motor vehicle involved crashes than bike only crashes and probably this is why the risk of facial fracture decreases with impact speed, although cannot be separated from other gradual changes, including overall cyclist experience, bicycling patterns and attitudes to risk, making it very difficult to correctly adjust for all relevant variables ${ }^{12,15,16}$. Moreover, a motor vehicle being involved does not tell us what the actual cause of the injury was: did the brakes fail and the cyclist collide with a car or did a car turn into a cyclist at a junction due to not seeing them. Juhra et al. ${ }^{11}$ had combined police and hospital data, which gives a larger statistical pool because some of the accidents involving the police are not severe enough to be treated in the hospital and vice versa.

In our series, mandibular fractures were the most frequent in bicycle injuries (49\%), and condylar fractures were the most common bicycling-related mandibular fracture $(63 \%)$ and seemed to be a common sequel to falls from bicycles where a direct collision on the chin, the most exposed area of the face in these accidents, creates a posterior impacting force that is transferred to the condyles ${ }^{17}$. This is explained because mandible is thicker inferiorly 
(symphysis area, horizontal ramus, mandibular angle) and thinner and more prone to fractures superiorly as they approach to the condylar neck. Swelling over the temporomandibular joint and restricted and painful jaw movement often accompanied these fractures. In fact, our algorithm for the management of these fractures included careful examination of these mandibular movements because this is essential to assess for these injuries.

A number of factors can decrease the risk of injuries. Previous studies have shown that the effectiveness of helmets in preventing head injuries is $65-88 \%{ }^{18}$; bicyclist helmets offer a substantial protective effect by reducing the risk for injuries to the part of the face that is near the edge of the helmet (mid-third and upper-third of the face), as in our series, and are likely to be the most effective in crashes without contact with a motorized vehicle or where the speeds are low and the cyclist is not run over ${ }^{18}$. Richard et al. ${ }^{19}$ reports that in France the use of helmets by cyclists has increased significantly the last decade, although both the information campaigns and the response by the population have not changed significantly the number of accidents. Castle et al. ${ }^{20}$ reports almost no change what so ever by the bicyclists in Los Angeles even after a law that makes bicycle helmets compulsory. In contrast to the former papers, Oliver et al. ${ }^{21}$ report a significant and steady decrease of head injury after a similar law was introduced in New South Wales. Although in our country, the Law on Road Safety requires wear a helmet in urban areas only to cyclist under 16 years, the analysis of our series indicate that the use of helmets should be strongly recommended in all age groups, although most commercially available helmets compliant with the European standard (EN-1078) do not protect the whole facial area and especially not the chin, and therefore are thought to offer too little protection in crashes cyclists are in collision with cars travelling at higher speeds ${ }^{22-24}$. Critics have raised questions over the actual efficacy of helmets by pointing to weaknesses in existing helmet epidemiology including selection bias and lack of appropriate control for the type of impact sustained by the cyclist and the severity of the head impact. We do not think that you can say that does not wear a helmet is a risk factor for injury, but obviously it may change the type of injury and reduce the severity of trauma, and therefore the improvement of the helmets design is one aspect that would be of interest for the prevention of injuries as it is the case with the bicycle helmets with airbag which currently provide better protection ${ }^{25}$. It has been shown previously that wearing helmets can prevent head injuries and helmet non-use has been shown to be strongly associated with severe head injury. Our study confirms the protective effects of helmet wearing. The risk for head injury, as well as admittance for those injuries which indicates the severity of these injuries, was statistically significantly increased for those who did not wear a helmet. The higher risk of head injury for non-users of helmets is consistent with other reports ${ }^{26}$. There are also more technologically advanced solutions that are being developed and which could have an important positive effect in the near futures. Anagnostopoulos et.al has developed a system which senses that a bike is approaching a traffic signal by detecting the mobile phone that the bicyclist almost certainly has. There are also many other systems based on ad-hoc networks, either between bikes or between can and bike. This gives the users an early warning that might help to prevent and accident.

This study has some limitations. The hospital involved in this study is referral service in the 
area of Andalusia (Spain), usually receiving and treating more complex craniofacial trauma. The sample is small because serious injuries occur relatively infrequently. Because of this factor, it is likely that the vast majority of patients with bicycle-related nasal fractures do not seek medical care in our department. Furthermore, a large percentage of condylar fractures have no clinically evident mandibular deviations, and therefore are likely missed by maxillofacial units, resulting in treatment simply with anti-inflammatory and analgesic drugs, and it is very common for patients to present with a remote history of condyle fracture and chronic functional temporomandibular problems.

\section{Conclusions:}

Maxillofacial trauma is a common injury, which can occur as a result of various causes. In this study, the cause and epidemiology of bicycle-related traumas to the face in cycle lanes in the city of Seville are reviewed. In our series, mandibular fractures were the most frequent in bicycle injuries, and condylar fractures were the most common bicycling-related mandibular fracture and seemed to be a common sequel to falls from a direct collision on the chin. Although bicycling-related maxillofacial fractures are rare, knowledge of their frequency, causes, risk factors, and anatomic distribution is important to units who have initial contact with patients presenting with a history of facial trauma sustained while practicing bicycle. Missed diagnosis or delayed treatment can lead to facial deformities and functional problems in the maxillofacial area. In our study, the most frequent risk factors for bicycle-related injuries were not wearing helmet, motor vehicle involved, driving with headphones, and early evening. These data may allow specific prevention strategies in bicycling-related maxillofacial fractures. Wearing protective helmets can more easily prevent head and face injuries in an attempt to make bicycling a safer activity, but prevention of these cannot be accomplished through helmet use alone and further prevention strategies are necessary in order to reduce the injury outcome.

\section{References:}

1. KOSTAKIS G, STATHOPOULOS P, DAIS P, GKINIS G, IGOUMENAKIS D, MEZITIS M, RALLIS G (2012). An epidemiologic analysis of 1,142 maxillofacial fractures and concomitant injuries. Oral Surg Oral Med Oral Pathol Oral Radiol. 114: pp. 69-73.

2. VAN HOUT WMMT, VAN CANN EM, ABBINK JH, KOOLE R (2013). An epidemiological study of maxillofacial fractures requiring surgical treatment at a tertiary trauma centre between 2005 and 2010. Br J Oral Maxillofac Surg. 51: pp. 416-20.

3. BOURDET N, DECK C, SERRE T, PERRIN C, LLARI M, WILLINGER R (2013). In-depth real-world bicycle accident reconstructions. Int J Crashworthiness 19: 222-32.

4. LEE KH, CHOU HJ (2008). Facial fractures in road cyclists. Aust Dent J. 53: 246-9.

5. PALMER AJ, SI L, GORDON JM, SAUL T, HITCHENS PL (2014). Accident rates amongst regular bicycle riders in Tasmania. Accid Anal Prev. 72: pp. 376-81.

6. WALKER P. World's best cycling cities. In: www.cnn.com/2014/08/17/travel/bestcycling-cities/ 
7. COPENHAGENIZE INDEX 2013. In: http://www.copenhagenize.eu/index/

8. LAWSON AR, PAKRASHI V, GHOSH B, SZETO WY (2013). Perception of safety of cyclists in Dublin City. Accid Anal Prev. 50: pp. 499-511.

9. VANDENBULCKE G, THOMAS I, DE GEUS B, DEGRAEUWE B, TORFS R, MEEUSEN R, INT PANIS L (2009). Mapping bicycle use and the risk of accidents for commuters who cycle to work in Belgium. Transport Policy 16: pp. 77-87.

10. WEBER T, SCARAMUZZA G, SCHMITT KU (2014). Evaluation of e-bike accidents in Switzerland. Accid Anal Prev. 73: pp. 47-52.

11. JUHRA C, WIESKOTTER B, CHU K, TROST L, WEISS U, MESSERSCHMIDT M, MALCZYK A, HECKWOLF M, RASCHKE M (2012). Bicycle accidents: Do we only see the tip of the iceberg? A prospective multi-centre study in a large German city combining medical and police data. Injury 43: pp. 2026-34.

12. VANDENBULCKE G, THOMAS I, INT PANIS, L (2014). Predicting cycling accident risk in Brussels: a spatial case-control approach. Accid Anal Prev. 62: pp. 341-57.

13. YAMAMOTO K, MATSUSUE Y, HORITA S, MURAKAMI K, SUGIURA T, KIRITA T (2011). Maxillofacial fractures sustained in bicycle accidents. J Oral Maxillofac Surg. 69: pp. 155-60.

14. BOFFANO P, ROCCIA F, GALLESIO C, KARAGOZOGLU KH, FOROUZANFAR T (2013). Bicycle-related maxillofacial injuries: A double-center study. Oral Surg Oral Med Oral Pathol Oral Radiol. 116: pp. 275-80.

15. THOMAS B, DEROBERTIS M (2013). The safety of urban cycle tracks: A review of the literature. Accid Anal Prev. 52: pp. 219-27.

16. VAN DER HORST AR, DE GOEDE M, DE HAIR-BUIJSSEN S, METHORST R (2014). Traffic conflicts on bicycle paths: A systematic observation of behaviour from video. Accid Anal Prev. 62: pp. 358-68.

17. SYED SH, WILLING R, JENKYN TR, YAZDANI A (2013). Video Analysis of the biomechanics of a bicycle accident resulting in significant facial fractures. $J$. Craniofacial Surg. 24: pp. 2023-9.

18. HAWORTH N, DEBNATH AK (2013). How similar are two-unit bicycle and motorcycle crashes? Accid Anal Prev. 58: pp. 15-25.

19. RICHARD JB, THELOT B, BECK F (2013). Evolution of bicycle helmet use and its determinants in France: 2000-2010. Accid Anal Prev. 60: pp. 113-20.

20. CASTLE SL, BURKE RV, ARBOGAST H, UPPERMAN JS (2012). Bicycle helmet legislation and injury patterns in trauma patients under age 18. J Surg Res. 173: pp. 32731.

21. OLIVIER J, WALTER SR, GRZEBIETA RH (2013). Long-term bicycle related head injury trends for New South Wales, Australia following mandatory helmet legislation. Accid Anal Prev. 50: pp. 1128-34.

22. CUMMINGS P, RIVARA FP, THOMPSON DC, THOMPSON RS (2006). Misconception regarding case-control studies of bicycle helmets and head injury. Accid Anal Prev. 38: pp. 636-43.

23. HANSEN K, DAU N, FEIST F, DECK C, WILLINGER R, MADEY SM, BOTTLANG M (2013). Angular Impact Mitigation system for bicycle helmets to reduce head acceleration and risk of traumatic brain injury. Accid Anal Prev. 59: pp. 109-17. 
24. MILNE G, DECK C, BOURDET N, CARREIRA RP, ALLINNE Q, GALLEGO A, WILLINGER R (2013). Bicycle helmet modelling and validation under linear and tangential impacts. Int J Crashworthiness 19: pp. 323-33.

25. RIZZI M, STIGSON S, KRAFFT M (2013). Cyclist injuries leading to permanent medical impairment in Sweden and the effect of bicycle helmets. Proceedings of the International Research Council on the Biomechanics of Injury Conference, Gothenburg, Sweden, 2013, pp. 412-423.

26. CRIPTON PA, DRESSLER DM, STUART CA, DENNISON CR (2014). Bicycle helmets are highly effective at preventing head injury during head impact: Head-form accelerations and injury criteria for helmeted and unhelmeted impacts. Accid Anal Prev. 70: pp. 1-7.

27. Theodoros Anagnostopoulos, Denzil Ferreira, Alexander Samodelkin, Muzamil Ahmed, Vassilis Kostakos, Cyclist-aware traffic lights through distributed smartphone sensing, Pervasive and Mobile Computing 